\title{
Characteristics of first-time fathers of advanced age: a Norwegian population-based study
}

\author{
Anne Britt Vika Nilsen ${ }^{1,2^{*}}$, Ulla Waldenström', Svein Rasmussen ${ }^{3}$, Anna Hjelmstedt ${ }^{1}$ and Erica Schytt ${ }^{1,4}$
}

\begin{abstract}
Background: The modern phenomenon of delayed parenthood applies not only to women but also to men, but less is known about what characterises men who are expecting their first child at an advanced age. This study investigates the sociodemographic characteristics, health behaviour, health problems, social relationships and timing of pregnancy in older first-time fathers.

Methods: A cross-sectional study was conducted of 14832 men who were expecting their first child, based on data from the Norwegian Mother and Child Cohort Study (MoBa) carried out by the Norwegian Institute of Public Health. Data were collected in 2005-2008 by means of a questionnaire in gestational week 17-18 of their partner's pregnancy, and from the Norwegian Medical Birth Register. The distribution of background variables was investigated across the age span of 25 years and above. Men of advanced age (35-39 years) and very advanced age (40 years or more) were compared with men aged 25-34 years by means of bivariate and multivariate logistic regression analyses.
\end{abstract}

Results: The following factors were found to be associated with having the first child at an advanced or very advanced age: being unmarried or non-cohabitant, negative health behaviour (overweight, obesity, smoking, frequent alcohol intake), physical and mental health problems (lower back pain, cardiovascular diseases, high blood pressure, sleeping problems, previous depressive symptoms), few social contacts and dissatisfaction with partner relationship. There were mixed associations for socioeconomic status: several proxy measures of high socioeconomic status (e.g. income $>65000 €$, self-employment) were associated with having the first child at an advanced or very advanced age, as were several other proxy measures of low socioeconomic status (e.g. unemployment, low level of education, immigrant background).The odds of the child being conceived after in vitro fertilisation were threefold in men aged 34-39 and fourfold from 40 years and above.

Conclusions: Men who expect their first baby at an advanced or very advanced age constitute a socioeconomically heterogeneous group with more health problems and more risky health behaviour than younger men. Since older men often have their first child with a woman of advanced age, in whom similar characteristics have been reported, their combined risk of adverse perinatal outcomes needs further attention by clinicians and researchers.

Keywords: Advanced paternal age, Postponing childbirth, Characteristics, First-time fathers

\footnotetext{
* Correspondence: abvn@hib.no

'Department of Women's and Children's Health, Karolinska Institutet,

Stockholm, Sweden

${ }^{2}$ Centre for Evidence Based Practice, Faculty of Health and Social Sciences,

Bergen University College, Postboks 7030, 5020, Bergen, Norway

Full list of author information is available at the end of the article
} 


\section{Background}

The modern phenomenon of delayed parenthood applies not only to women but also to men [1-3], and men are often around three years older than women when having their first child. In Norway during the period 1975 to 2011, the mean age of first-time fathers increased from 26 to 31 years, and in first-time mothers from 23 to 28 years (http://www.ssb.no/fodte/tab-2012-04-11-04. html). The postponement of parenthood has been explained by factors such as rising female employment, expansion of university education, gender equity, partnership formation, delays in leaving the parental home, financial insecurity among young adults, family policies and effective contraception $[4,5]$.

Research on obstetric and infant outcomes has mainly focused on the consequences of advanced maternal age $[5,6]$ and less on the role of fathers. However, a review by Sartorius and Nieschlag [7] concluded that increasing paternal age was not only associated with fertility problems, but also with miscarriage, fetal death, very preterm birth, preeclampsia, caesarean section, and offspring problems such as birth defects, schizophrenia, autism, and cancer. Most of the studies in the review controlled for maternal age. Infertility and adverse obstetric and infant outcomes were explained by the association of increasing paternal age with declining androgen levels, deterioration in sperm quality and influences on the DNA integrity of the sperm. The authors also discussed possible effects of age-related cofactors, such as vascular diseases, accumulation of toxic substances and infections of the reproductive accessory glands.

When discussing consequences of advanced maternal and paternal age, it is often argued that adverse health outcomes should be weighed up against potential social advantages for the children, because the parents are more likely to have progressed in their careers and to have financial security $[7,8]$. While this may be true for most children of older parents, our recent findings in a study of the characteristics of older first-time mothers suggest that the picture is more complex [9]. In addition to having more age-related reproductive and physical health problems, women of advanced age constituted a heterogeneous group characterised by either socioeconomic prosperity or vulnerability. On the one hand, high maternal age was associated with high annual income; and on the other hand with a low level of education, single status, unemployment, an unsatisfactory partner relationship and an unplanned pregnancy.

In the present study, our aim was to investigate whether this pattern also applied to older first-time fathers. Thus, the aim was not to identify the effect of advanced paternal age on pregnancy, childbirth and infant outcomes, but only to describe the characteristics of older first-time fathers. Specifically, the aims were: 1 ) to give an overview of characteristics at different ages when having the first child, from the age of 25 years and above; and 2) to investigate associations between advanced and very advanced paternal age respectively, and sociodemographic background, health behaviour, physical and mental health problems, social relationships, and whether pregnancy was planned or a result of medically assisted reproduction.

\section{Methods}

Selected data on first-time fathers were obtained from the Norwegian Mother and Child Cohort, a population-based cohort study conducted by the Norwegian Institute of Public Health. Participants were recruited from all over Norway from 1999-2008, and 38.5\% of the invited women consented to participate. The cohort now includes 108 000 children, 90700 mothers and 71500 fathers. The method is described in previous publications $[10,11]$. In the period from 2000 to 2008, fathers-to-be from all over Norway were recruited to the study through a postal invitation, which was sent to the mothers-to-be in connection with the routine ultrasound examination at 17-18 weeks of gestation. The woman was asked to forward the invitation and a questionnaire to the father-to-be, and if he agreed to participate in the study, he returned his signed informed consent form and the completed questionnaire to the research team. For the present study, selected data about first-time fathers who filled in the questionnaire from April 2005-2008 (version V) was used, since the questionnaire version used during this period included full information relevant for our study. Data were also retrieved from the questionnaires filled in by their partners at the same time point. To assess the representativity of the study sample, we used data from the Norwegian Medical Birth Register, which includes information about all deliveries in Norway [12].

\section{Paternal age}

Information about paternal age was obtained from the Norwegian Medical Birth Register and defined as age at the time of the baby's birth. There is no consensus regarding the definition of 'advanced' paternal age. We chose age cut-offs based on five-year intervals, as in many other studies [13-17], and defined 'advanced' age as 35-39 years and 'very advanced' as $\geq 40$ years. As a comparison group, we chose men aged 25-34 years, and excluded the youngest, who constitute a selected group with higher risk of negative exposures $[14,18]$.

\section{Descriptive variables}

Variables describing men's characteristics were classified into four blocks, in accordance with the second aim of the study. 


\section{Sociodemographics}

Block 1 included the following sociodemographic characteristics: mother tongue (Norwegian vs other than Norwegian), ongoing or completed education (primary school, secondary school, higher education $\leq 4$ years, higher education $>4$ years), employment (employed, selfemployed, student, unemployed/disabled/rehabilitation), annual income $(<200,000 \mathrm{NOK}-\geq 500,000 \mathrm{NOK})$ and civil status (married/cohabiting vs single).

\section{Health behaviour and health problems}

Block 2 included health behaviour at the time of early pregnancy: smoking (no, yes daily, yes sometimes), alcohol usage (frequency and amount), physical activity (frequency), body mass index; physical health problems: migraine, headache, asthma, diabetes, cancer, cardiovascular disease, high blood pressure, abdominal pain, Crohn's disease/ulcerative colitis, prolonged muscle pain, $\mathrm{Mb}$ Bechterew/rheumatoid arthritis, lower back pain, neck and shoulder pain, sexually transmitted diseases (chlamydia, genital herpes or warts, gonorrhoea); and mental health problems: sleeping problems, previous depressive symptoms, psychological distress. Questions about physical health problems and sleeping problems were phrased 'Do you have, or have you had any of the following illnesses or health problems? followed by a list of symptoms. Previous depressive symptoms were measured by the Lifetime Major Depression Scale [19]. After the question 'Have you ever experienced the following for a period of two weeks or more earlier in life?' the respondent was asked to tick yes or no after the following statements: ' $1=$ Felt depressed, sad', ' $2=$ Had problems with appetite or eaten too much', ' $3=$ Been bothered by feeling weak or lack of energy,' $4=$ Really blamed yourself and felt worthless,' $5=\mathrm{Had}$ problems with concentration or had problems making decisions', and ' $6=\mathrm{Had}$ at least three of the problems named above simultaneously'. Respondents who ticked yes on items 1 and 6 were classified as having previous depressive symptoms [20]. Current psychological distress was measured using a short form of the Symptom Checklist (SCL-5) [21,22]. The question 'Have you been bothered by any of the following feelings during the past two weeks?' was followed by the items: 'feeling fearful,' 'nervousness or shakiness inside, 'feeling hopeless about the future', 'feeling blue', and 'worrying too much about things'. Each item is scored on a 4-point scale ( $1=$ not bothered, $2=a$ little bothered, $3=$ quite bothered and $4=$ very bothered) with the total sum ranging from 5 to 20 . Mean scores were calculated and a cut-off at $\geq 2$ was defined as psychological distress [23].

\section{Present pregnancy}

Block 3 included variables retrieved from the partner's (woman's) questionnaire and related to whether the present pregnancy was unplanned (Yes/No). The woman was asked if she had been treated for infertility in relation to the present pregnancy, and if so what type of medically assisted reproduction (MAR) treatment she had received: hormone treatment, intra-vaginal insemination or in vitro fertilisation (IVF) [24].

\section{Social relationships}

Block 4 included the following variables related to social relationships: feeling lonely, having a support person other than partner, contacts with family and friends, and satisfaction with partner relationship. Satisfaction with partner relationship was measured using the five-item Relationship Satisfaction Scale [25], which is a shortened and modified version of the Marital Satisfaction Scale [26]. It includes the items: 'My partner and I have problems in our relationship,' 'I am very happy in my relationship', 'My partner is usually understanding,' 'I am satisfied with my relationship with my partner' and 'We agree about how children should be raised'. Each item is scored on a 6-point Likert scale with the end points 'Completely agree' and 'Disagree completely'. The total sum ranges from 5 to 30. A mean score was computed for each individual, which was then dichotomised into dissatisfied (score <4) and satisfied (scores 4-6) [25]. In cases of a maximum of two missing values on either of the two five-item scales, answers were imputed; imputation was performed in $0.8 \%$ of the cases on the SCL-5 scale, and in $1.2 \%$ of the cases on the Relationship Satisfaction Scale [27].

\section{Statistical analyses}

To assess the representativity of the study sample, we compared the men with all other first-time fathers in Norway in the same period, 2005-2008, using data from the Norwegian Medical Birth Register and the $\chi^{2}$-test for analysis. Figures were constructed showing the distribution of background characteristics by paternal age from 25 years to $\geq 45$ years, and also the fathers' age in relation to the age of the babies' mothers. To investigate possible associations between 'advanced' and 'very advanced' paternal age respectively and all the descriptive variables, analyses were conducted in three steps. First, all the variables were tested one by one in bivariate analyses. Second, a multivariate logistic regression analysis of the statistically significant variables was conducted for each block of variables. Third, final multivariate logistic regression models were constructed, one for each age category, in which blocks 1 to 4 were entered one by one in a sequential order. Variables were left in the models if statistically significant $(\mathrm{p}<0.05)$ in one or both age categories. Only the final models are presented as crude and adjusted odds ratios (OR) with 95\% confidence intervals (CI 95\%). Internal missing values were between $0.0-3.0 \%$, except for the alcohol variables $(3.2-3.4 \%)$ and social relationship 
variables (0.6-1.7\%). To retain cases with one or more missing values for categorical variables in the final model, a specific category 'missing' was constructed (not shown). Single imputations were made using Missing Value Analysis (MVA) and the Expectation Maximization (EM) algorithm method [28]. The remaining items on the scales were used as predictors for these imputations [27]. Collinearity for the final model was assessed using condition index.

The explained variance (Nagelkerke $R^{2}$ ) of the two models was calculated for each block separately when entered into the models (one by one), and the cumulative explained variance was calculated when each block was added to the preceding blocks in the order described above.

The Statistical Package SPSS for Windows, version 19.0 (SPSS INC., Chicago, Illinois, USA), was used for the statistical analyses. The study was approved by the Regional Committee for Ethics in Medical Research and the Norwegian Data Inspectorate: (S-97045) and (2012/ 198 B).

\section{Results}

A total of 127231 pregnant women were asked to forward an invitation also to the baby's father to join the Mother and Child Cohort study during the study period; 36879 (29\%) men consented to participate and received the questionnaire, and 33944 (92\%) actually responded. From this group, we excluded men who had at least one previous child ( $\mathrm{n}=17$ 925) and the youngest first-time fathers of $\leq 24$ years $(n=1187)$ who were beyond the scope of this study, leaving a final sample of 14832 firsttime fathers.

Table 1 shows the characteristics of the sample compared with all first-time fathers in Norway during the study period. Men in the study sample differed from those in the Norwegian cohort of new fathers aged 25 years and above: men aged 35-39 were slightly overrepresented and men $\geq 40$ years were slightly underrepresented. Additionally, more men in the study sample had a high level of education and fewer had a low level of education, or a mother tongue other than Norwegian.

Figure 1a shows that, although university/college education ( $>4$ years) and high annual income increased by paternal age, these outcomes peaked in men aged 33 and 42 years respectively, and were slightly less common in the oldest men. Unemployment, single status, and native languages other than Norwegian were somewhat more common among the oldest. Being overweight or obese seemed to increase with age (Figure 1b); physical and mental health problems increased from the age of about 35 years (Figure 1c, d); and, compared with the youngest group, the partner's pregnancy was more often planned or a result of IVF (Figure 1e). Social contacts with family, other than their partner, and friends seemed
Table 1 Characteristics of the study sample of first-time fathers ( $n=14832$ ) compared with all first-time fathers in Norway $(n=211762)$

\begin{tabular}{|c|c|c|c|c|c|}
\hline & $\begin{array}{l}\text { Study } \\
\text { sample }\end{array}$ & & $\begin{array}{l}\text { All first-time } \\
\text { fathers in } \\
\text { Norway* }\end{array}$ & & \\
\hline & $n$ & $\%$ & $n$ & $\%$ & $p$-value ${ }^{* *}$ \\
\hline Age groups & & & & & $<0.001$ \\
\hline 25-34 years & 11363 & 76.6 & 163063 & 77.0 & \\
\hline $35-39$ years & 2693 & 18.2 & 34291 & 16.2 & \\
\hline$\geq 40$ years & 776 & 5.2 & 14408 & 6.8 & \\
\hline $\begin{array}{l}\text { Mother tongue } \\
\text { other than } \\
\text { Norwegian }\end{array}$ & 1016 & 6.9 & 46293 & 21.9 & $<0.001$ \\
\hline Education & & & & & $<0.001$ \\
\hline Primary school & 288 & 2.0 & 29511 & 13.9 & \\
\hline Secondary school & 4862 & 33.7 & 87850 & 41.5 & \\
\hline $\begin{array}{l}\text { Higher education } \\
\leq 4 \text { years }\end{array}$ & 4301 & 29.8 & 53193 & 25.1 & \\
\hline $\begin{array}{l}\text { Higher education } \\
>4 \text { years }\end{array}$ & 4984 & 34.5 & 27635 & 13.1 & \\
\hline Unknown & 397 & 2.7 & 13573 & 6.4 & \\
\hline
\end{tabular}

*Data from the Norwegian Medical Birth Register.

**P-value for differences between the first-time fathers in the study sample and first-time fathers in Norway 2005-2008.

to decline gradually with age, but satisfaction with the partner relationship was about the same in all age groups (Figure 1f). Figure 2 shows the mean maternal age in relation to the age of first-time fathers. The mean age in the mothers increased with paternal age: the mean was 32.6 years and the median 33 for the partners of men of advanced age (35-39 years); and the mean was 35.1 years and the median 36 for the partners of men of very advanced age ( $\geq 40$ years). Having a partner younger than themselves was more common for fathers of advanced and very advanced age than for younger men.

Table 2 shows the crude and adjusted odds ratios for men of advanced age and very advanced age compared with the comparison group of 25-34 year-olds regarding sociodemographic characteristics (Block 1), health behaviour and health problems (Block 2), planning of pregnancy (Block 3) and social relationship variables (Block 4).

All sociodemographic variables differed from the comparison group. Unemployment, a low level of education and an immigrant background were features associated with having the first baby at an advanced or very advanced age, but affected only a few individuals. In contrast, the older men were more likely to have a high income ( $\geq 500000 \mathrm{NOK}$ (Norwegian krone) $\approx 65000 €$ ) and to be self-employed. The odds were nearly twofold and fourfold respectively that men of advanced and very advanced age would be unmarried or non-cohabiting. 


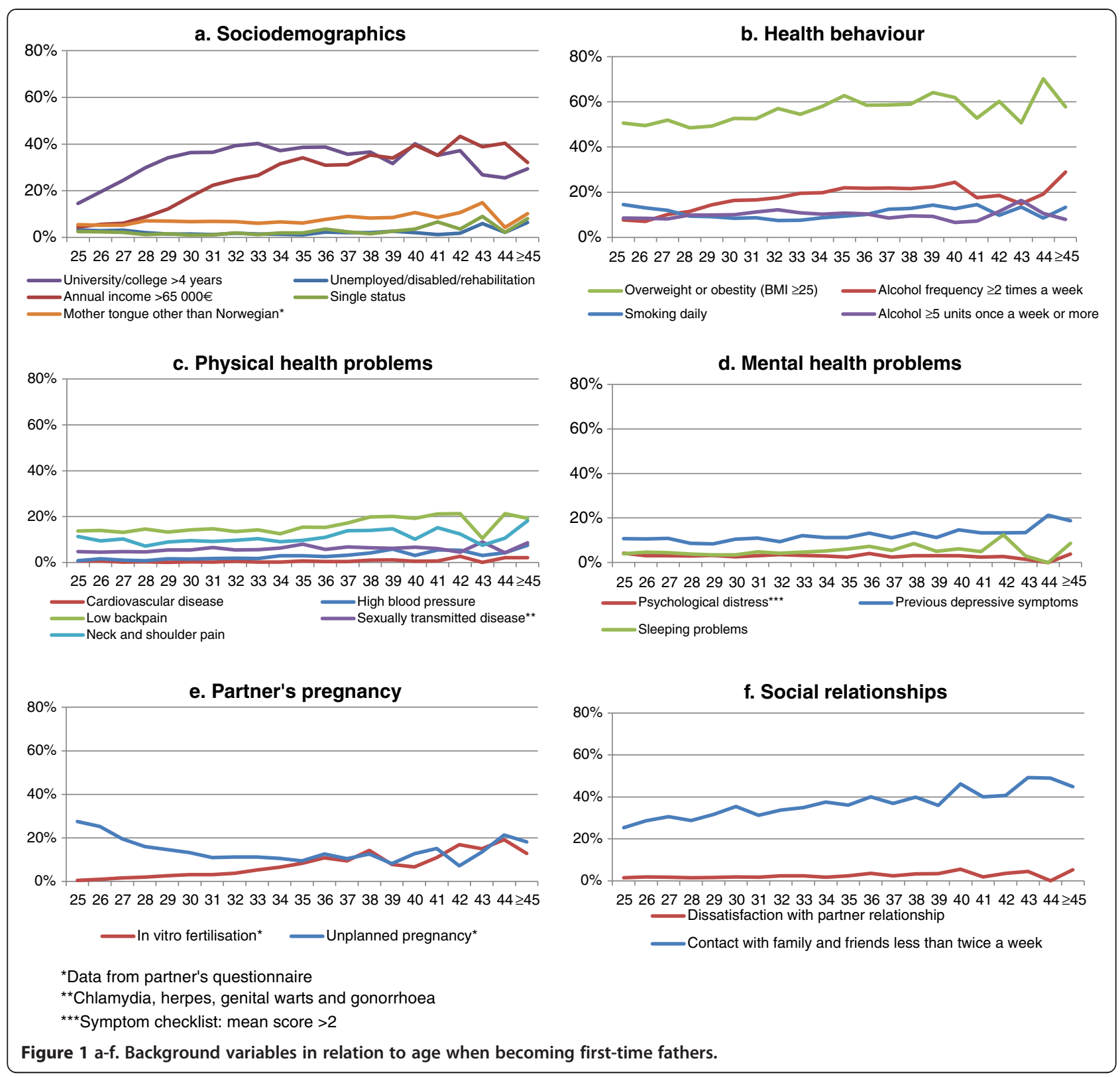

Health behaviour, physical and mental health problems also differed with age. The older men were more likely to be overweight or obese, to be smokers and to consume alcohol more frequently than the comparison group; however, they were less likely to be heavy consumers. Physical health problems, such as low back pain, were more common in older fathers, and most common in those of advanced age. Few were affected by cardiovascular disease and high blood pressure, but the odds were higher for the oldest groups compared with the youngest. The mental health problems associated with high paternal age were sleeping problems (advanced age), and previous depressive symptoms (advanced and very advanced age), but not ongoing psychological distress.

An unplanned pregnancy was as common in the oldest group as in the youngest, although less likely in men aged 35-39 years. The odds of the baby having been conceived after medically assisted reproduction were threefold in men aged 34-39 and fourfold from 40 years and above, compared with the youngest group.

Finally, limited contact with family and friends, and lack of support from others apart from their partner, was more common for the oldest men. Very few reported a poor partner relationship, but the relationship seemed most problematic for men aged 35-39. 


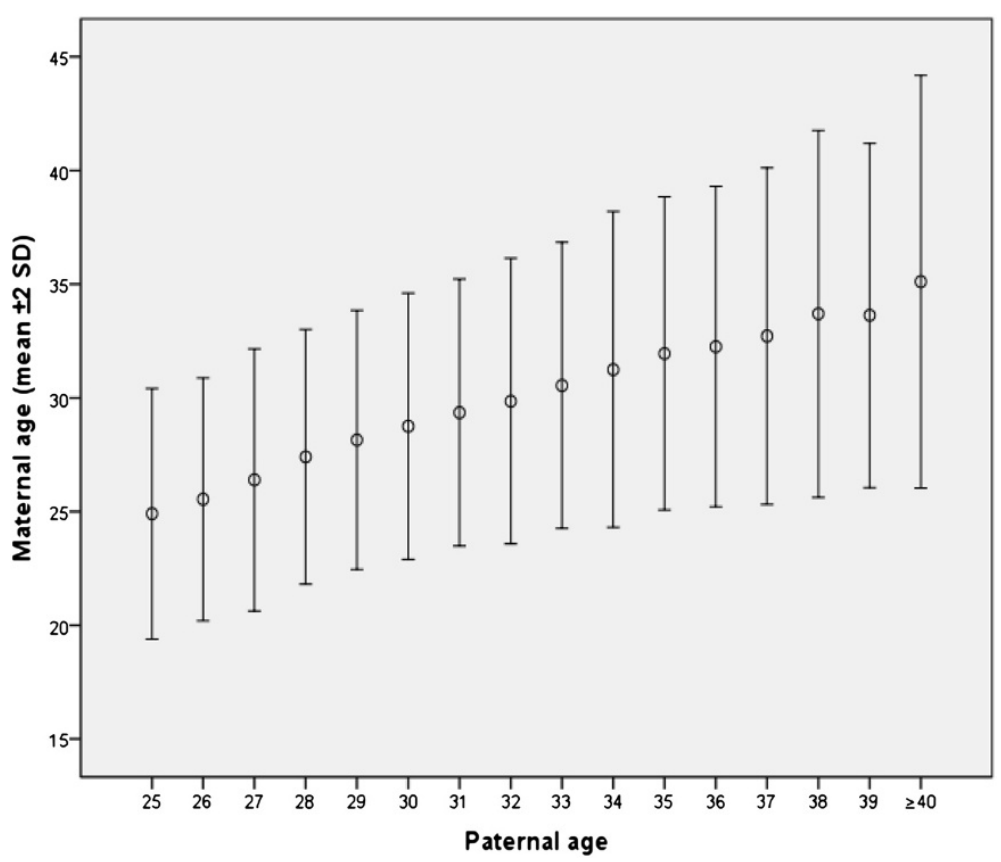

Figure 2 First-time father's age in relation to the age of his baby's mother (mean, $\pm 2 S D)$ ( $n=14832$ ).

The following variables were not associated with paternal age in either of the groups in the final model: physical activity, asthma, migraine, headache, diabetes, cancer, stomach-ache, Crohn's disease/ulcerative colitis, prolonged muscle pain, psychological distress and feeling lonely.

Table 3 shows that the models explained $12.7 \%$ (35-39 years) and $17.5 \%$ ( $\geq 40$ years) of the variance, respectively. In the older age groups, most of the variance, $6.8 \%$ and $7.9 \%$ respectively, was explained by sociodemographic factors.

\section{Discussion}

This study reveals that men who become fathers for the first time at an advanced (35-39 years) or very advanced age ( $\geq 40$ years) in Norway seem to constitute a heterogeneous group from a socioeconomic perspective: highincome earners were overrepresented, as well as men with a low level of education and men who were unemployed. It was also more common for the older men to be single or have less favourable social relationships, and they were at higher risk of negative health behaviour and health problems. Nevertheless, the vast majority lived up to the conditions set by many men when asked about the appropriate time for having the first baby; i.e. one should have a completed education, a permanent job and a stable financial situation, and be in a stable relationship $[29,30]$. Thus, the overall picture was very similar to the one reported in our previous study of first-time mothers [9].

As men do not face the same biological age limit for having children, more men than women have children at an advanced or very advanced age. Available data suggest that about $10 \%$ of fathers in the Nordic countries, Australia, England, Wales, and France are in their 40s, and a smaller percentage have children after 50 [5]. In the present population-based sample, $5.2 \%$ of the men were 40 years and above, compared with $6.8 \%$ in the national population of first-time fathers.

The medical risks associated with advanced paternal age have not gained the same level of attention as those related to advanced maternal age. This might be explained by the fact that men are able to become fathers later in life than women, and there has been less research into male factors than into those relating to females. The potential negative effect of advanced male age on reproductive outcome has been related to deterioration in sperm quality, but the specific age at which problems may occur cannot be easily defined. Studies of infertility are inconclusive; while one review has concluded that paternal age above the late 30s is a risk factor [31], another [7] specified that male age was a risk factor at least in couples where men are older than 40 and women are at least 35 years old. The present study only includes men where conception has been successful, and the issue of sperm quality in this context is relevant only in relation to its influence on obstetric and infant outcomes; however, many of the couples had experienced fertility problems.

The most important risk associated with advanced paternal age is related to having a baby with a woman of advanced age $[5,6]$. In first-time mothers, a range of obstetric and infant complications, such as caesarean section, 
Table 2 Associations between paternal age and sociodemographic characteristics (Block 1), health behaviour, physical and mental health problems (Block 2) partner's present pregnancy (Block 3) and social relationships (Block 4) in expectant first-time fathers (35-39 years and $\geq 40$ years) compared with a reference group aged 25-34 years

\begin{tabular}{|c|c|c|c|c|c|c|c|c|c|c|c|c|c|c|}
\hline & \multirow{2}{*}{\multicolumn{2}{|c|}{$\frac{25-34 \text { years }}{n=11363}$}} & \multicolumn{6}{|c|}{$35-39$ years } & \multicolumn{6}{|c|}{$\geq 40$ years } \\
\hline & & & \multicolumn{6}{|c|}{$n=2693$} & \multicolumn{6}{|c|}{$n=776$} \\
\hline & $\mathrm{n}$ & $\%$ & $\mathrm{n}$ & $\%$ & $\begin{array}{c}\text { Crude } \\
\text { OR }\end{array}$ & $(95 \% \mathrm{Cl})$ & $\mathrm{OR}^{\mathrm{a}}$ & $(95 \% \mathrm{Cl})$ & $n$ & $\%$ & $\begin{array}{c}\text { Crude } \\
\text { OR }\end{array}$ & $(95 \% \mathrm{Cl})$ & $\mathrm{OR}^{\mathrm{a}}$ & $(95 \% \mathrm{Cl})$ \\
\hline \multicolumn{15}{|c|}{ Sociodemographics (Block 1) } \\
\hline $\begin{array}{l}\text { Mother tongue other } \\
\text { than Norwegian bc }\end{array}$ & 733 & 6.5 & 205 & 7.6 & 1.19 & $(1.02-1.40)$ & 1.26 & $(1.06-1.50)$ & 78 & 10.1 & 1.62 & $(1.27-2.07)$ & 1.40 & $(1.07-1.84)$ \\
\hline \multicolumn{15}{|l|}{ Education } \\
\hline Primary school & 191 & 1.7 & 62 & 2.3 & 1.48 & $(1.10-1.99)$ & 1.55 & $(1.13-2.13)$ & 35 & 4.5 & 2.75 & $(1.88-4.03)$ & 2.67 & $(1.74-4.10)$ \\
\hline Secondary school & 3780 & 33.3 & 830 & 30.8 & ref & & ref & & 252 & 32.5 & ref & & ref & \\
\hline $\begin{array}{l}\text { Higher education } \\
\leq 4 \text { years }\end{array}$ & 3368 & 29.6 & 731 & 27.1 & 0.99 & $(0.89-1.10)$ & 0.96 & $(0.86-1.09)$ & 202 & 26.0 & 0.90 & $(0.74-1.09)$ & 0.90 & $(0.73-1.11)$ \\
\hline $\begin{array}{l}\text { Higher education } \\
>4 \text { years }\end{array}$ & 3720 & 32.7 & $\begin{array}{c}1 \\
000\end{array}$ & 37.1 & 1.22 & $(1.10-1.36)$ & 1.03 & $(0.91-1.16)$ & 264 & 34.0 & 1.06 & $(0.89-1.27)$ & 0.83 & (0.68-1.03) \\
\hline \multicolumn{15}{|l|}{ Employment } \\
\hline Employed & 8968 & 78.9 & $\begin{array}{c}2 \\
192\end{array}$ & 81.4 & ref & & ref & & 592 & 76.3 & ref & & ref & \\
\hline Self-employed & 1066 & 9.4 & 328 & 12.2 & 1.26 & $(1.10-1.44)$ & 1.42 & $(1.23-1.63)$ & 129 & 16.6 & 1.83 & $(1.50-2.24)$ & 1.92 & $(1.54-2.39)$ \\
\hline Student & 804 & 7.1 & 54 & 2.0 & 0.27 & $(0.21-0.36)$ & 0.51 & $(0.37-0.68)$ & 11 & 1.4 & 0.21 & $(0.11-0.38)$ & 0.39 & $(0.21-0.73)$ \\
\hline $\begin{array}{l}\text { Unemployed/disabled/ } \\
\text { rehabilitation }\end{array}$ & 216 & 1.9 & 50 & 1.9 & 0.95 & $(0.69-1.29)$ & 1.47 & $(1.04-2.08)$ & 25 & 3.2 & 1.75 & $(1.15-2.67)$ & 2.02 & $(1.23-3.33)$ \\
\hline \multicolumn{15}{|c|}{ Annual income NOK (Norwegian krone) } \\
\hline$<200000$ & 1271 & 11.2 & 114 & 4.2 & 0.46 & $(0.38-0.57)$ & 0.48 & $(0.38-0.60)$ & 39 & 5.0 & 0.61 & $(0.43-0.86)$ & 0.50 & $(0.33-0.74)$ \\
\hline 200-299999 & 1765 & 15.5 & 256 & 9.5 & 0.75 & $(0.64-0.87)$ & 0.69 & $(0.59-0.81)$ & 82 & 10.6 & 0.92 & $(0.71-1.20)$ & 0.69 & $(0.52-0.92)$ \\
\hline 300-399999 & 3995 & 35.2 & 775 & 28.8 & ref & & ref & & 201 & 25.9 & ref & & ref & \\
\hline 400-499 999 & 2262 & 19.9 & 633 & 23.5 & 1.44 & $(1.28-1.62)$ & 1.42 & $(1.26-1.60)$ & 155 & 20.0 & 1.36 & $(1.10-1.69)$ & 1.40 & $(1.12-1.76)$ \\
\hline$\geq 500000$ & 1916 & 16.9 & 887 & 32.9 & 2.39 & $(2.14-2.67)$ & 2.43 & $(2.16-2.73)$ & 290 & 37.4 & 3.01 & $(2.49-3.63)$ & 3.29 & $(2.68-4.04)$ \\
\hline \multicolumn{15}{|l|}{ Civil Status } \\
\hline Single status ${ }^{c}$ & 182 & 1.6 & 66 & 2.5 & 1.45 & $(1.09-1.94)$ & 1.90 & $(1.39-2.59)$ & 44 & 5.7 & 3.16 & $(2.23-4.48)$ & 3.58 & $(2.42-5.31)$ \\
\hline \multicolumn{15}{|c|}{ Health behaviour, physical and mental health problems(Block 2) } \\
\hline \multicolumn{15}{|l|}{$\begin{array}{l}\text { Body Mass Index } \\
\left(\mathrm{kg} / \mathrm{m}^{2}\right)\end{array}$} \\
\hline Normal (18.5-24.9) & 5319 & 46.8 & $\begin{array}{c}1 \\
050\end{array}$ & 39.0 & ref & & ref & & 322 & 41.5 & ref & & ref & \\
\hline $\begin{array}{l}\text { Overweight or obesity } \\
(\geq 25)\end{array}$ & 5967 & 52.5 & $\begin{array}{c}1 \\
629\end{array}$ & 60.5 & 1.38 & $(1.27-1.51)$ & 1.42 & $(1.29-1.55)$ & 452 & 58.2 & 1.25 & $(1.08-1.45)$ & 1.28 & $(1.09-1.50)$ \\
\hline Underweight $(<18.5)$ & 28 & 0.2 & 4 & 0.1 & 0.72 & $(0.25-2.07)$ & 0.84 & $(0.27-2.54$ & 1 & 0.1 & 0.59 & $(0.08-4.35)$ & 0.47 & $(0.05-4.19)$ \\
\hline \multicolumn{15}{|l|}{ Smoking ${ }^{c}$} \\
\hline Yes, sometimes & 1137 & 10.0 & 226 & 8.4 & 0.89 & $(0.76-1.03)$ & 0.99 & $(0.85-1.17)$ & 56 & 7.2 & 0.84 & $(0.63-1.12)$ & 0.92 & $(0.69-1.24)$ \\
\hline Yes, daily & 1075 & 9.5 & 302 & 11.2 & 1.26 & $(1.10-1.45)$ & 1.41 & $(1.21-1.65)$ & 98 & 12.6 & 1.52 & $(1.12-1.91)$ & 1.46 & $(1.13-1.89)$ \\
\hline \multicolumn{15}{|l|}{ Alcohol (frequency) } \\
\hline $\begin{array}{l}\text { Less than once a month } \\
\text { or never }\end{array}$ & 2535 & 22.3 & 523 & 19.4 & 0.68 & $(0.60-0.77)$ & 0.74 & $(0.65-0.84)$ & 161 & 20.7 & 0.57 & $(0.47-0.70)$ & 0.58 & $(0.46-0.72)$ \\
\hline Once a week/month & 6803 & 59.9 & $\begin{array}{c}1 \\
487\end{array}$ & 55.2 & ref & & ref & & 412 & 53.1 & ref & & ref & \\
\hline 2-3 times a week & 1482 & 13.0 & 489 & 18.2 & 1.74 & $(1.54-1.96)$ & 1.57 & $(1.39-1.79)$ & 131 & 16.9 & 1.84 & $(1.48-2.27)$ & 1.63 & $(1.30-2.04)$ \\
\hline 4-7 times a week & 187 & 1.6 & 101 & 3.8 & 2.84 & $(2.20-3.67)$ & 2.46 & $(1.88-3.20$ & 40 & 52 & 4.34 & $(2.97-6.34)$ & 3.59 & $(2.40-5.36)$ \\
\hline
\end{tabular}


Table 2 Associations between paternal age and sociodemographic characteristics (Block 1), health behaviour, physical and mental health problems (Block 2) partner's present pregnancy (Block 3) and social relationships (Block 4) in expectant first-time fathers (35-39 years and $\geq 40$ years) compared with a reference group aged 25-34 years (Continued)

Alcohol ( $\geq 5$ units $^{\mathrm{e}}$ when consuming)

\begin{tabular}{|c|c|c|c|c|c|c|c|c|c|c|c|c|c|c|}
\hline $\begin{array}{l}\text { Never or do not drink } \\
\text { alcohol }\end{array}$ & 1800 & 15.8 & 525 & 19.5 & 1.17 & $(1.04-1.32)$ & 1.51 & $(1.32-1.72)$ & 210 & 27.1 & 1.63 & $(1.39-1.96)$ & 2.25 & $(1.83-2.77)$ \\
\hline $\begin{array}{l}\text { Less than once } \\
\text { per month }\end{array}$ & 4447 & 39.1 & $\begin{array}{c}1 \\
107\end{array}$ & 41.1 & ref & & ref & & 318 & 41.0 & ref & & ref & \\
\hline 1-3 times per month & 3595 & 31.6 & 708 & 26.3 & 0.79 & $(0.71-0.88)$ & 0.67 & $(0.60-0.75)$ & 147 & 18.9 & 0.57 & $(0.47-0.70)$ & 0.44 & $(0.36-0.55)$ \\
\hline $\begin{array}{l}\text { Once or several times per } \\
\text { week }\end{array}$ & 1157 & 10.2 & 267 & 9.9 & 0.93 & $(0.80-1.08)$ & 0.64 & $(0.54-0.76)$ & 69 & 8.9 & 0.83 & $(0.64-1.09)$ & 0.50 & $(0.37-0.68)$ \\
\hline \multicolumn{15}{|l|}{ Physical health problems ${ }^{c}$} \\
\hline Cardiovascular disease & 33 & 0.3 & 17 & 0.6 & 2.18 & $(1.21-3.92)$ & 2.18 & $(1.16-4.09)$ & 10 & 1.3 & 4.48 & $(2.20-9.13)$ & 3.94 & $(1.79-8.66)$ \\
\hline ligh blood pressure & 179 & 1.6 & 90 & 3.3 & 2.16 & $(1.67-2.79)$ & 1.69 & $(1.29-2.22)$ & 39 & 5.0 & 3.31 & $(2.32-4.71)$ & 2.60 & $(1.76-3.83)$ \\
\hline Neck and shoulder pain & 1063 & 9.4 & 321 & 11.9 & 1.31 & $(1.15-1.50)$ & 1.20 & $(1.03-1.39)$ & 103 & 13.3 & 1.48 & $(1.19-1.84)$ & 1.09 & $(0.85-1.40)$ \\
\hline _ow back pain & 1571 & 13.8 & 453 & 16.8 & 1.26 & $(1.12-1.41)$ & 1.21 & $(1.07-1.37)$ & 150 & 19.3 & 1.49 & $(1.24-1.80)$ & 1.45 & $(1.18-1.79)$ \\
\hline Mb Bechterew & 63 & 0.6 & 16 & 0.6 & 1.07 & $(0.62-1.86)$ & 0.85 & $(0.48-1.52)$ & 13 & 1.7 & 3.06 & $(1.67-5.58)$ & 2.16 & $(1.11-4.21)$ \\
\hline $\begin{array}{l}\text { Sexually transmitted } \\
\text { diseases }^{d}\end{array}$ & 611 & 5.4 & 182 & 6.8 & 1.28 & $(1.07-1.51)$ & 1.26 & $(1.05-1.51)$ & 52 & 6.7 & 1.26 & $(0.94-1.69)$ & 1.32 & $(0.96-1.81)$ \\
\hline \multicolumn{15}{|l|}{ Mental health problems ${ }^{c}$} \\
\hline Sleeping problems & 476 & 4.2 & 174 & 6.5 & 1.58 & $(1.32-1.89)$ & 1.45 & $(1.19-1.77)$ & 52 & 6.7 & 1.64 & $(1.22-2.21)$ & 1.20 & $(0.86-1.69)$ \\
\hline $\begin{array}{l}\text { Previous depressive } \\
\text { symptoms }\end{array}$ & 1161 & 10.2 & 323 & 12.0 & 1.20 & $(1.05-1.37)$ & 1.22 & $(1.05-1.41)$ & 120 & 15.5 & 1.61 & $(1.31-1.97)$ & 1.44 & $(1.14-1.82)$ \\
\hline \multicolumn{15}{|l|}{ Present pregnancy ${ }^{p c}$ (Block 3) } \\
\hline \multicolumn{15}{|c|}{ Medically assisted reproduction } \\
\hline Hormone treatment & 302 & 2.7 & 106 & 3.9 & 1.63 & $(1.30-2.04)$ & 1.43 & $(1.13-1.81)$ & 32 & 4.1 & 1.75 & $(1.20-2.54)$ & 1.70 & $(1.16-2.52)$ \\
\hline Insemination & 21 & 0.2 & 14 & 0.5 & 3.09 & $(1.57-6.09)$ & 2.75 & $(1.34-5.63)$ & 3 & 0.4 & 2.36 & $(0.70-7.92)$ & 2.18 & $(0.60-7.90)$ \\
\hline In vitro fertilisation & 348 & 3.1 & 267 & 9.9 & 3.56 & $(3.01-4.20)$ & 3.12 & $(2.62-3.72)$ & 93 & 12.0 & 4.41 & $(3.46-5.62)$ & 4.13 & $(3.17-5.39)$ \\
\hline Unplanned pregnancy & 1695 & 14.9 & 290 & 10.8 & 0.69 & $(0.60-0.78)$ & 0.79 & $(0.68-0.91)$ & 111 & 14.3 & 0.96 & $(0.78-1.18)$ & 1.04 & $(0.82-1.31)$ \\
\hline
\end{tabular}

Social relationships (Block 4)

Contact with family

and friends

\begin{tabular}{|c|c|c|c|c|c|c|c|c|c|c|c|c|c|c|}
\hline More than twice a week & 7574 & 66.7 & $\begin{array}{c}1 \\
645\end{array}$ & 61.1 & ref & & ref & & 426 & 54.9 & ref & & ref & \\
\hline Twice a week or less & 3659 & 32.2 & $\begin{array}{c}1 \\
016\end{array}$ & 37.7 & 1.28 & $(1.17-1.40)$ & 1.22 & $(1.11-1.34)$ & 343 & 44.2 & 1.67 & $(1.44-1.93)$ & 1.48 & $(1.26-1.73)$ \\
\hline $\begin{array}{l}\text { No other support persons } \\
\text { than partner }\end{array}$ & 803 & 7.1 & 234 & 8.7 & 1.25 & $(1.07-1.45)$ & 1.14 & $(0.97-1.34)$ & 102 & 13.1 & 1.98 & $(1.59-2.47)$ & 1.55 & $(1.22-1.98)$ \\
\hline \multicolumn{15}{|l|}{ Partner relationship } \\
\hline $\begin{array}{l}\text { Satisfaction with partner } \\
\text { relationship }\end{array}$ & $\begin{array}{c}11 \\
044\end{array}$ & 97.2 & $\begin{array}{c}2 \\
593\end{array}$ & 96.3 & ref & & ref & & 739 & 95.2 & ref & & ref & \\
\hline issatisfaction with & 211 & 1.9 & 79 & 2.9 & 1.59 & $(1.23-2.07)$ & 1.48 & $(1.11-1.96)$ & 31 & 4.0 & 2.20 & $(1.50-3.22)$ & 1.52 & $(0.99-2.36)$ \\
\hline
\end{tabular}

partner relationship

Values shown for variables remaining in the final model only ( $n=14832, \%$ presented by column).

${ }^{a}$ Odds ratio adjusted for all other variables in the model.

${ }^{\mathrm{b}}$ Data from the partner's questionnaire.

'Reference: Men unexposed to the variable studied.

${ }^{\mathrm{d}}$ Chlamydia, genital herpes, genital wart, gonorrhoea.

${ }^{\mathrm{e}} 1.5 \mathrm{cl}$. pure alcohol. 
preterm birth, and perinatal mortality increase with age, particularly from the mid-30s [5,32]. In our study, the median age of the partners of men of advanced and very advanced age was 33 and 36 years respectively. Thus, about $50 \%$ of these men had a partner who was at risk of age-related complications. Little is known about the combined effect of expecting the first child at an advanced male and advanced female age. In their recent review of the consequences of postponement of parenthood, Schmidt et al. $[5,33]$ concluded that 'as women in general have partners who are several years older than themselves, it is important to focus more on the combined effect of advanced female and advanced male age on reproductive outcomes in the future.'

We are not aware of any negative obstetric complications associated with the higher prevalence of low education, unemployment and single status, among first-time fathers of very advanced age. These characteristics may be harder to accept at the age of 40 and above than earlier in life, and may have a negative influence on the relationship between the new parents and the social context in which the baby is born. These men do not fit into the general picture of men who postpone pregnancy in order to obtain a more stable start for the newborn baby. The small group of socioeconomically disadvantaged men may have a more challenging transition into fatherhood, finding it difficult to establish optimal conditions for developing contact and attachment with the baby [34]. A qualitative study showed that working-class fathers were less likely to be involved in childrearing than middle-class fathers, and that they more easily adopted the traditional gender role as breadwinner [35].

In addition to the independent effect of advanced male age on obstetric and neonatal outcomes [7], male age is associated with a lower chance of achieving a live birth by

Table 3 Explained variance (R2\% by Nagelkerke) of having the first baby at an advanced and very advanced paternal age; 35-39 years vs $\geq 40$ years, compared with men aged 25-34 years in four blocks of exposure variables $^{\mathrm{a}}$

\begin{tabular}{|c|c|c|c|c|}
\hline \multirow[b]{3}{*}{ Block $^{b}$} & \multicolumn{2}{|c|}{$\begin{array}{l}\text { Explained variance } \\
\text { of each block }\end{array}$} & \multicolumn{2}{|c|}{$\begin{array}{c}\text { Cumulative } \\
\text { explained variance }\end{array}$} \\
\hline & $35-39$ yrs & $\geq 40 \mathrm{yrs}$ & $35-39$ yrs & $\geq 40 \mathrm{yrs}$ \\
\hline & $\mathrm{R}^{2}$ & $\mathrm{R}^{2}$ & $\mathrm{R}^{2}$ & $\mathrm{R}^{2}$ \\
\hline Sociodemographics & 6.6 & 7.8 & 6.6 & 7.8 \\
\hline $\begin{array}{l}\text { Health behaviour, physical } \\
\text { and mental problems }\end{array}$ & 4.0 & 6.8 & 10.5 & 14.3 \\
\hline Planning of pregnancy & 2.7 & 2.7 & 12.5 & 16.5 \\
\hline Social relationships & 0.5 & 1.7 & 12.8 & 17.4 \\
\hline
\end{tabular}

${ }^{\mathrm{a}}$ Blocks entered either as first block (Explained variance of each block) or in sequential order (Cumulative explained variance).

${ }^{b}$ Variables in each block as in Table 2.
IVF/ICSI treatment [36]. The older men in our study were at higher risk than younger men of being overweight or obese, of having high blood pressure, and of practising risky behaviour such as smoking and frequent alcohol consumption. Some of these factors may affect reproductive outcomes. Smoking, for example, negatively affects sperm production, motility and morphology, and is associated with an increased risk of DNA damage [37,38]. Obesity may have an indirect effect by increasing the risk of cardiovascular disease, diabetes, and some cancers [39], in addition to a direct effect on time to pregnancy (TTP) $[33,40]$ especially in cases where also the woman is obese. Furthermore, the home environment in which the child will be brought up is influenced by the parents' health behaviour [41].

The strength of this study is the large sample of firsttime fathers, and data on fathers-to-be are seldom available from national statistics [1]. The low response rate may be a consequence of the recruitment process. Nonresponding and less advantaged women [9], or women who did not have any contact with the baby's father, would probably not assist in the recruitment by forwarding the invitation and questionnaire. Consequently the most vulnerable fathers-to-be, as well as couples, are not included in this study and the negative outcomes may therefore be underestimations.

\section{Conclusion and clinical implications}

The men who became fathers for the first time at an advanced age or very advanced age constituted a socioeconomically heterogeneous group, where the vast majority had a stable financial and social situation, and a minority was characterised by a low level of education, unemployment or single status. Health problems and risky health behaviour were more common than in younger men. Overall, the characteristics were very similar to those reported in older mothers-to-be. Our findings may modify a relatively common view that older first-time fathers constitute a homogeneous group of well-established and resourceful individuals. This information may help clinicians who care for expectant and new parents to provide more individualised care and support.

The higher rates of health problems and risky health behaviours in the men of advanced and very advanced age, and the fact that these men often had their first child with a woman of advanced age, suggest that the risk of adverse obstetric and perinatal outcomes would increase. Although it is beyond the scope of this study to draw conclusions about the effects of increased paternal age, our findings highlight characteristics of older firsttime fathers that should be further investigated, the most important being the combined effect of advanced paternal and maternal age. Even if specific knowledge about the combined effects is limited, there is sufficient 
evidence about the adverse negative effects of advanced maternal age on fertility and perinatal outcomes, and also about the negative effects of advanced paternal age on fertility and some infant outcomes, in order to support public health interventions focusing on information to young women and men, maybe already in school. There is, for example, a widespread misapprehension that assisted reproductive technology (ART) is a simple and effective solution to infertility problems. A Swedish study showed that male students were too optimistic regarding age-related female fecundity, and they also overestimated the chances of having a child through IVF treatment [30].

We therefore advocate that young women and men should be given more information about fecundity and the medical risks associated with postponing childbirth. Furthermore, we welcome investigations about effective incentives, such as facilitation of parental leave and improved financial conditions, for couples to conceive a few years earlier than is usual in modern societies of today.

\section{Competing interests}

The authors declare that they have no competing interests.

\section{Authors' contributions}

ABVN contributed to the planning of the study, and also analysed the data, contributed to the interpretation of findings and wrote the first draft of the manuscript. UW was the principal investigator and contributed with the idea, as well as to the interpretation of the results and the writing of the manuscript. AH contributed to the interpretation of results and by commenting on the manuscript. SR contributed in the analyses, and commented on the manuscript. ES contributed to the planning of the study, to the data analyses, to the interpretation of the results and to the writing of the manuscript. All of the authors have approved the final version of the manuscript.

\section{Acknowledgements}

The Norwegian Mother and Child Cohort Study is supported by the Norwegian Ministry of Health and the Ministry of Education and Research, $\mathrm{NIH/NIEHS} \mathrm{(contract} \mathrm{no} \mathrm{NO-ES-75558),} \mathrm{NIH/NINDS} \mathrm{(grant} \mathrm{no.1} \mathrm{UO1} \mathrm{NS}$ 047537-01), and the Norwegian Research Council/FUGE (grant no. 151918/ S10). This study was funded by the Swedish Research Council, Karolinska Institutet, Stockholm, Sweden and Bergen University College, Norway. We thank Professor Birgitte Espehaug for her helpful advice in the statistical analysis. We are grateful to all the participating families in Norway who take part in this ongoing cohort study.

\section{Author details}

'Department of Women's and Children's Health, Karolinska Institutet, Stockholm, Sweden. ${ }^{2}$ Centre for Evidence Based Practice, Faculty of Health and Social Sciences, Bergen University College, Postboks 7030, 5020, Bergen, Norway. ${ }^{3}$ Institute of Clinical Medicine, University of Bergen, Bergen, Norway. ${ }^{4}$ Centre for Clinical Research Dalarna, Falun, Sweden.

Received: 4 September 2012 Accepted: 24 January 2013

Published: 30 January 2013

\section{References}

1. PriouX F: Late fertility in Europe: some comparative and historical data. Rev Epidemiol Sante Publique 2005, 53(Spec No 2):2S3-11.

2. Office for National Statistics: Patterns of fatherhood in England and Wales, 1964-2007. Popul Trends 2009, 136:103-107. Crown copyright.

3. Coleman D: Male fertility trends in industrial countries: theories in search of some evidence. In Fertility and the male life-cycle in the era of fertility decline. Edited by Bledsoe $\mathrm{CH}$, Lerner S, Guyer Jl. Oxford: Oxford University Press; 2000:29-60.

4. Mills M, Rindfuss RR, McDonald P, te Velde E, Reproduction obotE, Force ST: Why do people postpone parenthood? Reasons and social policy incentives. Hum Reprod Update 2011, 6(17):848-860.

5. Schmidt L, Sobotka T, Bentzen JG, Nyboe Andersen A: Demographic and medical consequences of the postponement of parenthood. Hum Reprod Update 2012, 18(1):29-43.

6. Tournaye H: Male reproductive ageing. In Reproductive aging. Edited by Bewley S, Ledger W, Nikolaou D. London: RCOG Press; 2009.

7. Sartorius GA, Nieschlag E: Paternal age and reproduction. Hum Reprod Update 2010, 16(1):65-79.

8. Stein Z, Susser M: The risks of having children in later life. Social advantage may make up for biological disadvantage. Bmj 2000, 320(7251):1681-1682.

9. Nilsen $A B$, Waldenstrom U, Hjelmsted A, Rasmussen $S$, Schytt E: Characteristics of women who are pregnant with their first baby at an advanced age. Acta Obstet Gynecol Scand 2012, 91(3):353-362x.

10. Magnus P, Irgens LM, Haug K, Nystad W, Skjaerven R, Stoltenberg C, The Moba Study Group: Cohort profile: The Norwegian Mother and Child Cohort Study (MoBa). Int J Epidemiol 2006, 35(5):1146-1150.

11. Nilsen RM, Vollset SE, Gjessing HK, Skjaerven R, Melve KK, Schreuder P, Alsaker ER, Haug K, Daltveit AK, Magnus P: Self-selection and bias in a large prospective pregnancy cohort in Norway. Paediatr Perinat Epidemiol 2009, 23(6):597-608.

12. Irgens LM: The Medical Birth Registry of Norway. Epidemiological research and surveillance throughout 30 years. Acta Obstet Gynecol Scand 2000, 79(6):435-439.

13. Schmidt L: Infertility and assisted reproduction in Denmark. Epidemiology and psychosocial consequences. Dan Med Bull 2006 53(4):390-417.

14. Chen XK, Wen SW, Krewski D, Fleming N, Yang Q, Walker MC: Paternal age and adverse birth outcomes: teenager or $40+$, who is at risk? Hum Reprod 2008, 23(6):1290-1296

15. Yip BH, Pawitan Y, Czene K: Parental age and risk of childhood cancers: a population-based cohort study from Sweden. Int I Epidemiol 2006, 35(6):1495-1503.

16. Ford WC, North K, Taylor H, Farrow A, Hull MG, Golding J: Increasing paternal age is associated with delayed conception in a large population of fertile couples: evidence for declining fecundity in older men. The ALSPAC Study Team (Avon Longitudinal Study of Pregnancy and Childhood). Hum Reprod 2000, 15(8):1703-1708.

17. Nybo Andersen AM, Hansen KD, Andersen PK, Davey Smith G: Advanced paternal age and risk of fetal death: a cohort study. Am J Epidemiol 2004, 160(12):1214-1222.

18. Bunting L, McAuley C: Research Review: Teenage pregnancy and parenthood: the role of fathers. Child \& Family Social Work 2004, 9(3):295-303.

19. Kendler KS, Neale MC, Kessler RC, Heath AC, Eaves LJ: The lifetime history of major depression in women. Reliability of diagnosis and heritability. Arch Gen Psychiatry 1993, 50(11):863-870.

20. Nes RB, Clech-Aas J: Mental Health in Norway: tilstandsrapport med internasjonale sammenligninger, vol. 2011:2. Oslo: Nasjonalt folkehelseinstitutt; 2011.

21. Tambs K, Moum T: How well can a few questionnaire items indicate anxiety and depression? Acta Psychiatr Scand 1993, 87(5):364-367.

22. Derogatis L: SCL-90-R: Administration, Scoring and Procedures Manual - II. Towson: C.P. Research; 1983.

23. Strand BH, Dalgard OS, Tambs K, Rognerud M: Measuring the mental health status of the Norwegian population: A comparison of the instruments SCL-25, SCL-10, SCL-5 and MHI-5 (SF-36). Nord J Psychiatry 2003, 57(2):113-118.

24. Zegers-Hochschild F, Adamson GD, de Mouzon J, Ishihara O, Mansour R, Nygren $K$, Sullivan E, van der Poel S: The International Committee for Monitoring Assisted Reproductive Technology (ICMART) and the World Health Organization (WHO) Revised Glossary on ART Terminology, 2009. Hum Reprod 2009, 24(11):2683-2687.

25. Røysamb E, Vittersø J, Tambs K: The Relationship Satisfaction Scale. Reliability, validity, and goodness of fit (review)., In process.

26. Blum JS, Mehrabian A: Personality and temperament correlates of marital satisfaction. J Pers 1999, 67(1):93-125.

27. Marti $\mathrm{H}$, Chavance M: Multiple imputation analysis of case-cohort studies. Stat Med 2011, 30(13):1595-1607. 
28. Dempster AP, Laird NM, Rubin DB: Maximum likelihood from incomplete data via the EM algorithm. J R Stat Soc 1977, 39(B, 39,B, 39):1-38.

29. Thompson R, Lee C: Sooner or later? Young Australian men's perspectives on timing of parenthood. J Health Psychol 2011, 16(5):807-818.

30. Lampic C, Svanberg AS, Karlstrom P, Tyden T: Fertility awareness, intentions concerning childbearing, and attitudes towards parenthood among female and male academics. Hum Reprod 2006, 21(2):558-564.

31. De La Rochebrochard E, Mcelreavey K, Thonneau P: Paternal Age Over 40 Years: The "Amber Light" in the Reproductive Life of Men? J Andro/ 2003, 24(4):459-465.

32. Flenady V, Koopmans L, Middleton P, Froen JF, Smith GC, Gibbons K, Coory $M$, Gordon A, Ellwood D, McIntyre HD, et al: Major risk factors for stillbirth in high-income countries: a systematic review and meta-analysis. Lancet 2011, 377(9774):1331-1340.

33. Ramlau-Hansen CH, Thulstrup AM, Nohr EA, Bonde JP, Sørensen TIA, Olsen J: Subfecundity in overweight and obese couples. Hum Reprod 2007, 22(6):1634-1637

34. Schytt E, Hildingsson I: Physical and emotional self-rated health among Swedish women and men during pregnancy and the first year of parenthood. Sex Reprod Healthc 2011, 2(2):57-64.

35. Ny P, Plantin L, Dejin-Karlsson E, Dykes AK: The experience of Middle Eastern men living in Sweden of maternal and child health care and fatherhood: focus-group discussions and content analysis. Midwifery 2008, 24(3):281-290

36. Pinborg A, Gaarslev C, Hougaard CO, Nyboe Andersen A, Andersen PK, Boivin J, Schmidt L: Influence of female bodyweight on IVF outcome: a longitudinal multicentre cohort study of 487 infertile couples. Reprod Biomed Online 2011, 23(4):490-499.

37. Zenzes MT, Bielecki R, Reed TE: Detection of benzo(a)pyrene diol epoxideDNA adducts in sperm of men exposed to cigarette smoke. Fertil Steril 1999, 72(2):330-335.

38. Kunzle $\mathrm{R}$, Mueller MD, Hanggi W, Birkhauser $\mathrm{MH}$, Drescher $\mathrm{H}$, Bersinger NA Semen quality of male smokers and nonsmokers in infertile couples. Fertil Steril 2003, 79(2):287-291.

39. Homan GF, Davies M, Norman R: The impact of lifestyle factors on reproductive performance in the general population and those undergoing infertility treatment: a review. Hum Reprod Update 2007, 13(3):209-223

40. Hassan MA, Killick SR: Effect of male age on fertility: evidence for the decline in male fertility with increasing age. Fertil Steril 2003 79(Suppl 3):1520-1527.

41. Edvardsson K, Ivarsson A, Eurenius E, Garvare R, Nystrom ME, Small R, Mogren I: Giving offspring a healthy start: parents' experiences of health promotion and lifestyle change during pregnancy and early parenthood. BMC public health 2011, 11:936.

doi:10.1186/1471-2393-13-29

Cite this article as: Nilsen et al:: Characteristics of first-time fathers of advanced age: a Norwegian population-based study. BMC Pregnancy and Childbirth 2013 13:29.

\section{Submit your next manuscript to BioMed Central and take full advantage of:}

- Convenient online submission

- Thorough peer review

- No space constraints or color figure charges

- Immediate publication on acceptance

- Inclusion in PubMed, CAS, Scopus and Google Scholar

- Research which is freely available for redistribution 